\title{
CORRIGENDUM
}

\section{High nitrous oxide production from thawing permafrost}

Bo Elberling, Hanne H. Christiansen and Birger U. Hansen

Nature Geoscience 3, 332-335 (2010); published online: 4 April 2010; corrected after print: 26 May 2010.

In the version of this Letter originally published, Fig. $2 \mathrm{~b}$ was incorrect and should have been as shown here. This error has been corrected in the HTML and PDF versions of the Letter.

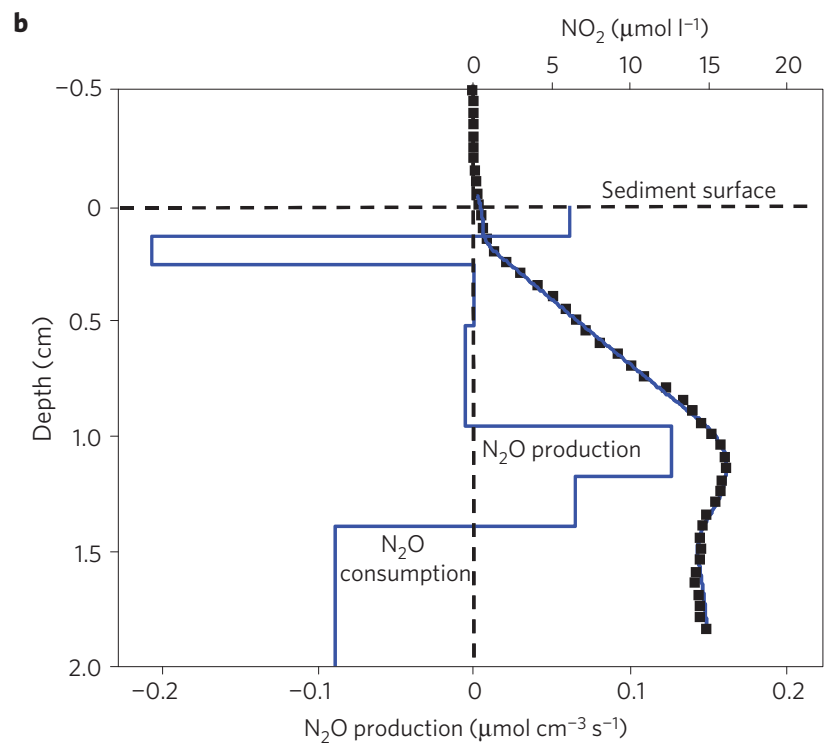

